\title{
Obesity: Anaesthetic implications and considerations-a review
}

\author{
Obezite: Anestetik etkileri ve özellikleri-derleme
}

Teena Bansal*, Sarla Hooda

Department of Anaesthesiology \& Critical Care ((T. Bansal, DA, DNB, S. Hooda, MD), University of Health Sciences, Rohtak-124001 India

\begin{abstract}
The obese patient presents many challenges to anaesthesiologist. A good understanding of the pathophysiologic effects of obesity and its anaesthetic implications is important. The anaesthesiologist must recognize increased risks and comorbidities inherent to the obese patient and manage accordingly, optimizing multisystem function in the perioperative period that leads to successful outcomes. Perioperative issues such as intravenous access, difficulty in measuring non invasive blood pressure, difficult spinal, epidural and difficult airway should be anticipated and planned.
\end{abstract}

Keywords: Obesity, anaesthesia, anaesthetic considerations

\section{Özet}

Obez hastalar anestezistlere çeşitli sorunlar çıkarır. Obezitenin patofizyolojik etkileri ve anesteziklerle etkileşimlerinin iyi anlaşılması önemlidir. Anestezistler obez hastalardaki risk ve komorbidite artışlarını farketmeli ve perioperatif dönemde başarılı sonuçlar elde edebilmek için multisistem fonksiyonlarını optimize ederek buna göre hareket etmelidir. İntravenöz girişim, noninvaziv kan basıncı ölçümü, spinal-epidural anestezi ve havayolu ulaşımındaki zorluklar önceden tahmin edilerek gerekli planlama yapılmalıdır.

Anahtar sözcükler: Obezite, anestezi, anestetik özellikleri

Geliş tarihi/Received: March 01, 2014; Kabul tarihi/Accepted: August 18, 2014

\section{*Corresponding author:}

Dr. Teena Bansal, Department of Anaesthesiology and Critical Care, University of Health Sciences, Rohtak-124001 India. E-mail: aggarwalteenu@rediffmail.com

\section{Introduction}

The population of obese people is increasing in both developed and developing countries and hence anaesthetists are more frequently facing challenges while managing obese patients. Obese patients may present for any type of surgery including elective surgery, emergency surgery, obstetric anaesthesia and analgesia. Therefore thorough understanding of the pathophysiology and complications associated with obesity will allow more effective anaesthetic management of this group of patients. Preoperative assessment and preparation, choice of anaesthetic technique, patient positioning and handling and postoperative care all require special consideration in these patients.

\section{Definition}

The word obesity is derived from Latin word obesus which means flattened by eating. It is a condition in which body fat is in excess. The most common used method to measure obesity is body mass index (BMI) which is equal to weight/ height $2\left(\mathrm{~kg} / \mathrm{m}^{2}\right)$ also known as Quetelet's index. A BMI of $<25 \mathrm{~kg} / \mathrm{m}^{2}$ is considered normal, a person with a BMI of $25-30 \mathrm{~kg} / \mathrm{m}^{2}$ is considered overweight but at low risk of serious medical complications, 
while those with a BMI of $>30,>35$ and $>55 \mathrm{~kg} / \mathrm{m}^{2}$ are considered obese, morbidly obese and super morbidly obese respectively [1]. Although BMI is the most commonly used tool for assessing the severity of obesity, it is not necessarily the best clinical predictor of disease. The distribution of adipose tissue rather than the absolute weight or BMI appears to be more clinically relevant. Android obesity which is truncal distribution of fat is associated with high incidence of cardiovascular disorders and gynecoid obesity where fat is distributed to thighs and buttocks is not linked to cardiovascular problems [2, 3].

\section{Changes in various systems in obesity}

\section{Respiratory system}

Obesity is associated with decreased lung and chest wall compliance, increased airway resistance and reduced functional residual capacity. Functional residual capacity often falls below the closing capacity, resulting in atelectasis, ventilation/perfusion mismatch and impaired oxygenation. The supine position and induction of anaesthesia further compound these effects [4]

\section{Obstructive sleep apnoea (OSA)}

Obesity may be associated with obstructive sleep apnoea which is defined as apnoeic episodes secondary to pharyngeal collapse that occurs during sleep. The characteristic features of obstructive sleep apnoea are:

1. Frequent episodes of apnoea or hypopnoea during sleep. An obstructive apnoeic episode is defined as $10 \mathrm{sec}$ or more of total cessation of airflow despite continuous respiratory effort against a closed airway. Hypopnoea is defined as $50 \%$ reduction in airflow or a reduction sufficient to lead to a $4 \%$ decrease in arterial oxygen saturation. The number of episodes five or more per hour or $>30$ per night are thought to be clinically significant $[5,6]$.

2. Snoring

3. Day time somnolence associated with impaired concentration and morning headaches.

4. Pathophysiological changes-hypoxemia leading to secondary polycythaemia and hence associated with an increased risk of ischemic heart disease and cerebrovascular disease, hypercapnia, systemic vasoconstriction or pulmonary vasoconstriction leading to right ventricular failure [7].

The features that help to identify OSA are a BMI $>30 \mathrm{~kg} / \mathrm{m}^{2}$, hypertension, observed episodes of apnoea during sleep, polycythemia, hypoxia/hypercapnia and right ventricular hypertrophy. Definitive diagnosis is made by polysomnography in a sleep laboratory.

\section{Obesity hypoventilation syndrome (OHS)}

It is a long term consequence of OSA associated with a progressive desensitization of the respiratory centres to hypercapnia, initially limited to sleep but eventually lead to type II respiratory failure with an increasing reliance on hypoxic drive for ventilation. OHS culminates in Pickwickian syndrome, which is characterized by obesity, hypersomnolence, hypoxia, hypercapnia, right ventricular failure and polycythemia [8].

OSA is associated with difficulty in effective mask ventilation and hypoxemic events. These patients can be treated with nocturnal continuous positive airway pressure (CPAP) preoperatively. It is recommended that patients on home CPAP should bring their device with them for immediate use postoperatively and CPAP device should be on standby during anaesthesia recovery for these patients with OSA.

\section{Cardiovascular system}

Obesity is associated with ischemic heart disease, hypertension and cardiac failure. Obesity is associated with increase in blood volume and cardiac output. Increased activity in the renin angiotensin system and secondary polycythemia play a role in volume 
expansion which results in increased blood volume. Blood is distributed mainly to tissues with increased fat deposition, cerebral and renal blood flows are relatively unchanged. Increase in cardiac output occurs as a result of ventricular dilation and an increase in stroke volume. The ventricular dilation results in increased left ventricular wall stress leading to hypertrophy. Eccentric left ventricular hypertrophy results in reduced compliance and left ventricular diastolic function i.e. impairment of ventricular filling, leading to elevated left ventricular end diastolic pressure and pulmonary oedema. The capacity of the dilated ventricle to hypertrophy is limited, so when left ventricular wall thickening fails to keep pace with dilation, systolic dysfunction ensues [9]. Arrythmias may be precipitated in these patients by hypoxia, hypercapnia, electrolyte disturbance by diuretics, coronary artery disease, OSA, myocardial hypertrophy and fatty infiltration of the conduction system.

\section{Gastrointestinal system}

Obese patients have a high incidence of diabetes. They should be assessed for the adequacy of glucose control e.g. glycosylated hemoglobin and also for the presence of complications of diabetes especially cardiac disease, renal disease and autonomic dysfunction. These patients are also at increased risk for aspiration of gastric contents with induction of anaesthesia because of combination of increased intraabdominal pressure, high volume and low $\mathrm{pH}$ of gastric contents and an increased incidence of gastro-oesophageal reflux [10]. Precautions against aspiration in the form of $\mathrm{H}_{2}$ receptor antagonists, antacids, prokinetics, rapid sequence induction with cricoid pressure and tracheal intubation with the patient fully awake should be taken [11].

\section{Thromboembolism}

Prolonged immobilization in addition to polycythemia, increased abdominal pressure and decreased fibrinolytic activity leads to increased risk of thromboembolism in these patients and measures to prevent this problem should always be taken [8].

\section{Preoperative assessment}

The objective of preoperative assessment is to optimize the patient's outcomes. It enables timely identification and treatment of preexisting medical condition and determines how each patient should be managed pre and postoperatively. All patients should have their height and weight recorded and the BMI calculated and recorded. Special attention should be paid to comorbidities which place obese patients at higher risk e.g. hypertension, dyslipidaemia, ischemic heart disease, diabetes mellitus, osteoarthritis and liver disease. Interventions that can reduce risk include weight loss, exercise training and treatment of obstructive sleep apnoea [12].

\section{Respiratory assessment}

Baseline respiratory function should be established from the patient history and physical examination. Room air pulse oximetry may be a useful screening tool for further investigations. A supine arterial oxygen saturation $\left(\mathrm{SpO}_{2}\right)<96 \%$ on room air may indicate that further investigations (spirometry, arterial blood gases) are appropriate.

\section{Cardiovascular assessment}

Preoperative assessment facilitates thorough evaluation of cardiac risk and implementation of medical measures whenever possible, to minimize risk. Cardiac function can be difficult to ascertain in these patients from clinical history, as mobility is frequently limited. Asking the patient to walk the length of the yard may reveal a markedly reduced exercise tolerance. The patient should have a detailed and thorough cardiovascular examination, looking in particular for evidence of hypertension (with an appropriately sized BP cuff) and cardiac failure. An electrocardiography (ECG) is mandatory preoperatively. Echocardioraphy can provide useful information about the cardiac status of the patient. 


\section{Airway assessment}

Most airway catastrophes occur when airway difficulty is not recognized before induction of anaesthesia. A careful and detailed assessment of the obese patients' airway should be done before they are anaesthetized. Obese patients have a higher potential for difficult mask ventilation, laryngoscopy and intubation. These problems are caused by certain features like fat face and cheeks, large breasts, short neck, large tongue, excessive palatal and pharyngeal soft tissue, high and anterior larynx, restricted mouth opening and limitation of cervical spine and atlantooccipetal flexion and extension [13]. Absolute weight and BMI are poor predictors of difficult tracheal intubation, whereas large neck circumference $(>40 \mathrm{~cm})$, Mallampati score $>3$ and thyromental distance $<6 \mathrm{~cm}$ are more specific indicators of difficult intubation [14]. In addition, history of OSA implies potential airway obstruction once the patient has been rendered unconscious.

\section{Preoperative special issues and considerations}

\section{Operating table}

Selection of appropriate operating table should be done before surgery. Standard monitoring tables can hold upto $450 \mathrm{lbs}$ but tables capable of holding upto $1000 \mathrm{lbs}$ are available. An appropriately sized operating table is imperative. The use of two operating tables (side by side) can be considered. The problem with this technique is that it is impossible to raise, lower or change the position of the tables in a completely synchronous manner [15].

\section{Positioning the patient}

Positioning the obese patient is a challenge for the operating room team. Ulnar neuropathy is the most frequent perioperative positioning complication in obese patients [16]. Once the patient is in position, particular care should be paid to protecting pressure areas. Careful and appropriate positioning of all body areas must be repeatedly reevaluated by the vigilant anaesthesiologists as changes in operating table position, members of the surgical team leaning against the patient and spontaneous movement of the patient may lead to undesirable positioning outcomes [17].

\section{Anaesthetic management}

Perioperative issues such as intravenous access, difficulty in measuring non invasive blood pressure, difficult spinal, epidural and difficult airway should be anticipated and planned. Venous cannulation can be difficult and central venous cannulation may be required.

\section{Choice of anaesthesia}

\section{Regional anaesthesia}

Regional anaesthesia, whenever possible, is the best choice in obese patients. The use of regional anaesthesia in these patients reduces the risk of difficult intubation and acid aspiration and also provides safer and more effective postoperative analgesia [18]. Regardless of anaesthetic technique chosen, preparation for general anaesthesia and difficult intubation including assortment of Laryngeal mask airways, short handled laryngoscope and fiberoptic bronchoscope must be in place in addition to experienced hands.

Technical problem associated with regional anaesthesia in obese patient includes difficulty in identification of anatomical landmarks. Sitting position if preferred and larger needles may be required. Ultrasound is useful in the obese patient to identify the epidural space and to guide the Touhy needle into position [19]. Local anaesthetic requirements for epidural and spinal anaesthesia are reduced to $75-80 \%$ of normal in the morbidly obese, since fatty infiltration and the increased blood volume caused by increased intraabdominal pressure reduce the volume of the epidural space. This can lead to unpredictable spread of local anaesthetic and variability in block height [8]. 


\section{General anaesthesia}

Ramped position accomplished by arranging blankets underneath the patients' upper body and head until horizontal alignment is achieved between the external auditory meatus and the sterna notch clearly improves the laryngeal view when compared with the standard "sniff" position. HELP (head elevated laryngoscopy position) should be given to make sure that airway is in alignment [20]. Preoxygenation in the 25 degree head up position and the application of preinduction positive end expiratory pressure (PEEP, 10 $\mathrm{cm} \mathrm{H} 2 \mathrm{O}$ for 5 minutes), followed by $10 \mathrm{~cm} \mathrm{H}_{2} \mathrm{O}$ PEEP prior to intubation has been shown to prolong the duration of non hypoxic apnoea in patients with a BMI $>35 \mathrm{~kg} / \mathrm{m}^{2}[21,22]$. When general anaesthesia is administered without anticipation of difficult airway, rapid sequence induction is recommended. Awake fiberoptic intubation should be considered in case of difficult airway. A difficult airway cart that includes laryngeal mask airways, gum elastic bougie, a long blade of laryngoscope, polio handle, Mccoy laryngoscope, video laryngoscope, fiberscope and equipment for emergency surgical airway should be available. The use of short acting anaesthetic agents such as remifentanil, sevoflurane or desflurane helps to aid rapid recovery from anaesthesia and minimize postoperative hypoventilation and hypoxemia. Monitoring of neuromuscular block is essential, as incomplete reversal of neuromuscular blocking agents is poorly tolerated in obesity and can have disastrous consequences [23]. Extubation should be done awake in reverse trendelenburg position.

\section{Monitoring}

Unless the length of the cuff exceeds the circumference of the arm by $20 \%$, systolic and diastolic blood pressure measurements may overestimate the patients' blood pressure. Direct arterial blood pressure may be useful in these patients, when sphygmomanometry is often inaccurate. Pulse oximetry, ECG, capnography and monitoring of neuromuscular block are all mandatory. Use of central venous and pulmonary artery catheters should be considered in patients undergoing extensive surgery or those with serious cardiopulmonary disease.

\section{Drug usage in obesity-specific considerations}

Opioid and sedative drugs may cause respiratory depression, so these drugs are best avoided in premedication. Also the intramuscular and subcutaneous routes should be avoided since absorption is very unreliable. Obesity alters the pharmacokinetics of most drugs. Highly lipophilic substances such as barbiturates and benzodiazepines show significant increase in volume of distribution in obese individuals and the dosing should be based on total body weight for lipophilic agents. Less lipophilic compounds have little or no change in volume of distribution with obesity and the doses should be based on ideal body weight for these agents. Exception to above are remifentanil and succinylcholine. Remifentanil is a highly lipophilic but shows no significant change in distribution in obese patients. Consequently, the absolute volume of distribution remains relatively unchanged and the dosage should be calculated on the basis of ideal body weight. Dosage of succinylcholine should be calculated using total body weight [17].

\section{Postoperative care and specific precautions}

Thromboembolism and pulmonary complications are the greatest postoperative risk. Mobilisation and incentive spirometry are key in preventing postoperative complications.

To conclude anaesthetic management of an obese patient is a challenge to the anaesthesiologist. Thorough understanding of the pathophysiology and complications associated with obesity allows more effective anaesthetic management of these patients. Patients should be thoroughly assessed and managed preoperatively. Regional anaesthesia whenever possible scores over general anaesthesia. 


\section{References}

1. Bray GA. Pathophysiology of obesity. Am J Clin Nutr 1992; 55: 488-94.

2. Bray GA. Complications of obesity. Ann Intern Med 1985; 103: 1052-62.

3. Jensen MD. Health consequences of fat distribution. Horm Res 1997; S48: 88-92.

4. Koenig SM. Pulmonary complications of obesity. Am J Med Sci 2001; 321: 24979.

5. Douglas NJ, Polo O. Pathogenesis of obstructive sleep apnoea/ hypopnoea syndrome. Lancet 1994; 344: 653-5.

6. Vgontzas AN, Tan TL, Bixler EO, Martin LF, Shubert D, Kales A. Sleep apnea and sleep distribution in obese patients. Arch Int Med 1994; 154: 1705-11.

7. Lotia S, Bellamy MC. Anaesthesia and morbid obesity.Critical Care \& Pain 2008; 8: 151-6.

8. Adams JP, Murphy PG. Obesity in anaesthesia and intensive care. Br J Anaesth 2000; 85: 91-108.

9. Alpert MA, Hashimi MW. Obesity and the heart. Am J Med Sci 1993; 306: 11723.

10. Vaughan RW, Bauer S, Wise L. Volume and $\mathrm{pH}$ of gastric juice in obese patients. Anesthesiology 1975; 43: 686-9.

11. Bansal T, Hooda S. Awake intubation- a viable approach for preventing aspiration in patients undergoing emergency surgery after administration of oral contrast material. Egyptian Journal of Anaesthesia 2013; 29: 179-80.

12. Neill T, Allam J. Anaesthetic considerations and management of the obese patient presenting for bariatric surgery. Current anaesthesia \& Critical Care 2010; 21: 16-23.

13. Brodsky JB. Anesthetic management of the morbidly obese patient. Int Anesthesiol Clin 1986; 24: 93-103.

14. Brodsky JB, Lemmens HJ, Brock-Utne JG, Vierra M, Saidman LJ. Morbid obesity and tracheal intubation. Anesth Analg 2002; 94: 732-6.

15. Rao DP, Rao VA. Morbidly obese parturient. Challenges for the anaesthesiologist, including managing the difficult airway in obstetrics. What is new? Indian J Anaesth 2010; 54: 508-21.

16. Warner MA, Warner DO, Harper CM, Schroeder DR, Maxson PM. Ulnar neuropathy in medical patients. Anesthesiology 2000; 92: 613-5.

17. Dority J, Hassan Z, Chau D. Anesthetic implications of obesity in the surgical patient. Clin Colon Rectal Surg 2011; 24: 222-8.

18. Bansal T, Kumar P, Hooda S. Regional anaesthesia-still a comfortable choice in morbidly obese parturient. Colombian Journal of Anaesthesiology 2013; 41: 3025.

19. Wallace DH, Currie JM, Gilstrap LC, Santos R. Indirect sonographic guidance for epidural anaesthesia in obese pregnant patients. Reg Anesth 1992; 17: 233-6.

20. Shah N, Lattoo Y. Anaesthetic management of obese parturient. BJMP 2008; 1: 15-23.

21. Dixon BJ, Dixon JB, Carden JR, Burn AJ, Schachter LM, Playfair JM. Preoxygenation is more effective in the 25 head up position than in the supine position in severely obese patients: A randomized controlled study. Anesthesiology 2005; 102: 1110-5.

22. Gander S, Frascarolo P, Suter M, Spahn DR, Magnusson L. Positive end expiratory pressure during induction of general anaesthesia increases duration of non hypoxic apnea in morbidly obese patients. Anesth Analg 2005; 100: 580-4.

23. Ankichetty SP, Angle P, Joselyn AS, Chinnappa V, Halpern S. Anesthetic considerations of parturients with obesity and obstructive sleep apnea. J Anaesthesiol Clin Pharmacol 2012; 28: 436-43. 